\title{
Time domain reflectometry for dielectric characterization of olive mill wastewater contaminated soils
}

\author{
Alessandro Comegna, ${ }^{1}$ Antonio Coppola, ${ }^{1}$ Giovanna Dragonetti ${ }^{2}$ \\ ${ }^{1}$ School of Agricultural Forestry Food and Environmental Sciences (SAFE), University of Basilicata, Potenza; \\ ${ }^{2}$ Mediterranean Agronomic Institute, Land and Water Division, IAMB, Bari, Italy
}

\begin{abstract}
Olive mill wastewater (OMW) is a compound originating from oil mills during oil extraction processes. In the Mediterranean area, more than 30 million $\mathrm{m}^{3}$ of OMW are produced each year, which represents $95-97 \%$ of the world production. Such volumes of untreated OMW are usually directly disposed of into drainage systems, water bodies (such as streams, lagoons and ponds) or are sprinkled on soils, causing potentially severe environmental problems to soils and groundwater. Consequently, there is a serious waste management problem related to the olive oil industry, because these practices no longer being acceptable. In the case of on-land OMW disposal, the characterization and the identification of this contaminant in soils is a fundamental task especially with a view to maintaining the integrity and quality of agroecosystems. In recent years, soils have been extensively studied to detect contaminants by using various geophysical methods. Among such techniques, time domain reflectometry (TDR) has shown, in different contexts, evident sensitivity and resolution capability for the characterization of contaminated soil sites. In order to further exploit the potential of the TDR technique, in this study we conducted a series of laboratory-controlled tests to explore how OMW influences the dielectric response of contaminated soils. This investigation led to the development of an empirical dielectric model to estimate the presence of OMW in variably saturated-contaminated soils with different textures and pedological features. In particular, the soils selected belong to two typical pedological units in southern Italy which
\end{abstract}

Correspondence: Alessandro Comegna, School of Agricultural Forestry Food and Environmental Sciences (SAFE), University of Basilicata, via Nazario Sauro 85, 85100 Potenza, Italy.

Tel.: +39.0971205474.

E-mail: alessandro.comegna@unibas.it

Key words: Soil contamination; soil-olive mill wastewater mixtures; dielectric models; time domain reflectometry.

Received for publication: 16 June 2020.

Accepted for publication: 30 July 2020.

${ }^{\circ}$ Copyright: the Author(s), 2020

Licensee PAGEPress, Italy

Journal of Agricultural Engineering 2020; LI:1092

doi:10.4081/jae.2020.1092

This article is distributed under the terms of the Creative Commons Attribution Noncommercial License (by-nc 4.0) which permits any noncommercial use, distribution, and reproduction in any medium, provided the original author(s) and source are credited. account for approximately $90 \%$ of the Italian olive plantations and one of the highest concentrations of the olive oil industry in Italy. In these districts, as well as in other European and Mediterranean countries, there is the controversial habit to spread OMW on soils.

\section{Introduction}

The olive oil industry is one of the main agricultural sectors in the Mediterranean basin. Every year about 2 million tons of olive oil are produced (Piotrowska et al., 2011), and this production is steadily increasing (Caputo et al., 2013; Sahraoui et al., 2015).

The extraction process of olive oil generates olive mill wastewater (OMW) which is a mixture of vegetation water initially present in the drupes and the water used during the different stages of oil extraction (Colarieti et al., 2006; Sahraoui et al., 2015). The volumes of OMW produced depend on the extraction method (i.e., traditional pressing, or two-phase/three-phase centrifugation systems) and may vary between 40 and 100 liters per $100 \mathrm{~kg}$ of processed olives (Kavvadias et al., 2014).

OMW is a waste product with a high pollution load. It is generally characterized by a low $\mathrm{pH}$, high salinity and organic content, high chemical and biological oxygen demand, a high concentration of suspended solids, and abundant presence of mineral elements especially nitrogen, phosphorus, potassium, calcium and magnesium (Mekki et al., 2006). Furthermore, considerable concentrations of phenolic compounds may be detectable in this wastewater with concentrations usually varying between 1.0 and 10 g/L (Capasso et al., 1992; Piotrowska et al., 2011).

Due to its complex composition, OMW cannot be directly added to domestic wastewater treatment plants (Caputo et al., 2013), and there is a lack of practical and sustainable alternative solutions for OMW disposal. This aspect represents a potential environmental problem for olive oil-producing countries (Kavvadias et al., 2014). One solution adopted for OMW discharge, which has been legally regulated in several countries, is its use for soil fertilization. However, the benefits of this practice are questionable due to its proven toxic effect on the soil biota (Isidori et al., 2005). Furthermore, long-term OMW application may cause severe alteration of soil chemical and physical properties.

For all the above reasons, the problem of evaluating the spatial and temporal distribution of OMW in situ represents a research topic of paramount interest. For example, it can now be faced by using non-invasive geophysical methods (Huisman et al., 2003; Robinson et al., 2003).

Starting from the findings of Comegna et al. (2016), in this study we show the suitability of the time domain reflectometry (TDR) technique in determining the presence of OMW in a contaminated medium. Indeed, we observed that OMW affected the dielectric behaviour of the contaminated soil. A direct dependence 
of the bulk electrical conductivity $\left(E C_{b}\right)$ on OMW concentration was experimentally documented. This dependence was investigated in depth and exploited to develop, calibrate and validate a dielectric logarithmic model, which provided the possibility of quantifying the presence of OMW, under different levels of soil contamination.

\section{Dielectric permittivity and electrical conductivity deter- mination using time domain reflectometry}

TDR allows concomitant determination of soil bulk dielectric permittivity $\left(\varepsilon_{b}\right)$ and soil bulk electrical conductivity $\left(E C_{b}\right)$ on the same observation volume (Dalton et al., 1984). The $\varepsilon_{b}$ determined by TDR requires the measurement of the propagation velocity and attenuation of an applied electromagnetic wave along a transmission line in the soil (Topp et al., 1980). At TDR frequencies between $200 \mathrm{MHz}$ to $1.0 \mathrm{GHz}$, the dielectric losses can be assumed to be negligible, and $\varepsilon_{b}$ along a wave-guide line of length $L$ is a function of the propagation velocity $v(=2 L / t)$ according to:

$\varepsilon_{b}=\left(\frac{c}{v}\right)^{2}=\left(\frac{c t}{2 L}\right)^{2}$

where $c\left(=3 \times 10^{8} \mathrm{~m} \mathrm{~s}^{-1}\right)$ is the velocity of an electromagnetic wave in vacuum, and $t$ is the travel time, that is the time that the TDR signal requires to travel to and from the wave-guide.

The attenuation of the TDR signal can also be used as a measure of $E C_{b}$. According to the thin section approach, originally proposed by Giese and Tiemann (1974), $E C_{b}$ can be calculated as follows:

$$
E C_{b}=\frac{\varepsilon_{0} c}{L} \frac{Z_{0}}{Z_{c}}\left(\frac{2 V_{0}}{V_{f}}-1\right)
$$

where $\varepsilon_{0}$ is the dielectric permittivity of free space, $Z_{0}$ is the characteristic probe impedance, $Z_{c}$ is the TDR cable tester output impedance, $V_{0}$ is the incident pulse voltage, and $V_{f}$ is the return pulse voltage at relatively long distances along the waveform (Or et al., 2004).

\section{Volumetric olive mill wastewater content determination in soils}

The detection of contaminants in multiphase soil systems by means of geophysical methods is problematic, even if the pollutant is homogeneously distributed within the soil matrix (Redman and De Ryck, 1994; Persson and Berndtsson, 2002; Haridy et al., 2004; Moroizumi and Sasaki, 2006; Francisca and Montoro, 2012). The TDR technique has the potential to reveal the presence of a contaminant in soils (Comegna et al., 2013a; Comegna et al., 2016; Comegna et al., 2017; Comegna et al., 2019). However, as the TDR waveform only returns aggregate information that depends on all the distinct phases involved (Comegna et al., 2016), the challenge is to find a way to infer the dielectric weight of the pollutant from the whole dielectric response (Comegna et al., 2013b).

In this research work, we followed the same methodological approach applied by Comegna et al. (2016), which was developed to detect and quantify the presence of organic contaminants, such as non-aqueous phase liquids (NAPLs) in variable saturated soils. We observed that the presence of a NAPL in the soil affected the dielectric response of the medium in terms of bulk dielectric permittivity ( $e_{b}$ decreases as the amount of NAPL increases). The analysis of dielectric NAPL behaviour allowed us to establish a univocal relationship between the amount of NAPL in the contaminated soil $\left(\theta_{N A P L}\right)$, the bulk dielectric permittivity of the multiphase medium $\left(\varepsilon_{b}\right)$, and the final value of the reflection coefficient $\left(\rho_{f}\right)$ which, as known, can only be determined at long TDR-travel times (Or et al., 2004). Starting from these findings, we concentrated our efforts on OMWs, which are fluids with dielectric characteristics that are quite unlike those of NAPLs.

In the case of OMWs, we observed that their presence in soils scarcely alters the global dielectric response of the medium in terms of permittivity, which varies randomly with increasing amounts of OMW (see section below). By contrast, at higher propagation times (i.e., those useful for TDR- $E C_{b}$ calculation), a functional relationship between $\theta_{O M W}$ and $E C_{b}$ can be hypothesized. Such considerations allowed us to develop, in the contaminated medium, a logarithmic relationship between $E C_{b}$, and the so-called relative volume of OMW in water $(\beta)$ :

$$
\beta=a \ln \left(E C_{b}\right)+b
$$

where $a$ and $b$ were the coefficients which had to be experimentally determined (i.e., site specific), and the relative volume of OMW in water, $\beta$, was defined as (Rinaldi and Francisca, 2006):

$$
\beta=\frac{\theta_{\text {OMW }}}{\left(\theta_{w}+\theta_{\text {OMW }}\right)}=\frac{\theta_{\text {OMW }}}{\theta_{f}}
$$

where $\theta_{f}$ and $\theta_{w}$ were respectively the volumetric content of the whole fluid phase and the volumetric water content. Values of $\beta$ varied in the range between 0 for a soil-water mixture and 1 for a soil-OMW mixture.

By substituting Equation 4 into Equation 3, $\theta_{O M W}$ can be calculated as:

$$
\theta_{\text {OMW }}=\theta_{f}\left[a \ln \left(E C_{b}\right)+b\right]
$$

We observed that, for a selected soil, coefficients $a$ and $b$ depended on $\theta_{f}$ values (see section below), in the sense that for each $\theta_{f}$ a pair of $a$ and $b$ parameters can be estimated. Further data examination coupled with statistical analysis based on an ANCOVA test, which was conducted at a significance level of $\alpha=0.05$ (for more details see Comegna et al., 2016), allowed us to assume the coefficient $a$ of Equation 5 to be constant ( $\alpha=\alpha=$ cost, thus independent of $\theta_{f}$ ), whereas the term $b$ could be related to $\theta_{f}$ via a second-order polynomial equation:

$$
b=b_{1} \theta_{f}^{2}+b_{2} \theta_{f}+b_{3}
$$

where $b_{1}, b_{2}$ and $b_{3}$ were fitting parameters of the equation.

As a result, $\theta_{O M W}$ could be finally written as follows:

$$
\theta_{\text {OMW }}=\theta_{f}\left[a_{c} \ln \left(E C_{b}\right)+\left(b_{1} \theta_{f}^{2}+b_{2} \theta_{f}+b_{3}\right)\right]
$$

Using Equation 7, $\theta_{O M W}$ could be estimated once the bulk electrical conductivity $\left(E C_{b}\right)$ and the volumetric fluid content $\left(\theta_{f}\right)$ of the contaminated medium were determined. It should be empha- 
sized that the methodology developed can be successfully applied in those situations where the practice of OMW sprinkling on soils is a priori known. In such field conditions, OMW can indeed be considered the dominant factor that influences the dielectric behaviour of soils, mainly in terms of $E C_{b}$ values, as clearly shown in the sections below.

\section{Materials and methods}

\section{Soil and olive mill waastewater properties}

The soils selected to conduct this research work were a loam Eutric Cambisol (IUSS Working Group WRB, 2006) and a siltloam Anthrosol (IUSS Working Group WRB, 2006), both of which are found in Southern Italy. Table 1 reports the main physical and chemical properties of the two soils, while Table 2 shows a characterisation of the OMW employed in the laboratory experiments.

The total polyphenol content was obtained using FolinCiocalteu colorimetric method (APHA, 1995). Absorbance was measured at $760 \mathrm{~nm}$ with a SpectroVis Plus (Vernier Software \& Technology) UV-visible spectrophotometer. Total nitrogen (TN), total organic content (TOC) and chemical oxygen demand (COD) were determined by using the IRSA-CNR 4060 method (IRSACNR, 2003), the IRSA-CNR 5040 method (IRSA-CNR, 2003) and the IRSA-CNR 5130 method (IRSA-CNR, 2003), respectively.

\section{Experimental equipment}

The experimental apparatus consisted of a TDR unit (Tektronix $1502 \mathrm{C}$ cable tester) and a three-wire TDR probe (with wave guides $14.5 \mathrm{~cm}$ long) connected via an RG58 coaxial cable to the tester. The TDR signals once acquired were post-processed for $\varepsilon_{b}$ and $E C_{b}$ calculation with a homemade Matlab code. The laboratory system used during the experiments is illustrated in Figure 1.

\section{Laboratory experiments}

The laboratory experiments were carried out on repacked soil samples. Simultaneous measurements of $\varepsilon_{b}$ and $E C_{b}$ were made on soil samples that were adequately prepared as a mix of known amounts of soil and volumetric water $\left(\theta_{w}\right)$ and OMW $\left(\theta_{O M W}\right)$ content, following the scheme reported in Table 3. Soil samples were oven dried at $105^{\circ} \mathrm{C}$ and sieved at $2 \mathrm{~mm}$. The different combinations of soil, water and OMW were mixed and then kept for $24 \mathrm{~h}$ in plastic bags to ensure that OMW and water were uniformly distributed within the soil. Since the TDR signal (hence the dielectric response of a medium) is influenced by soil porosity $\phi$ (Jung et al., 2013), soil samples were cautiously placed in plastic cylindrical containers (15 cm high and $9.5 \mathrm{~cm}$ in diameter) until the bulk densities of $1.27 \mathrm{~g} \mathrm{~cm}^{-3}$ (Eutric Cambisol) and $1.13 \mathrm{~g} \mathrm{~cm}^{-3}$ (Anthrosol) were reached. Finally, a TDR probe was inserted vertically into the samples. The same procedure was replicated on a second set of samples for model validation. The laboratory tests were conducted at a constant temperature of $25^{\circ} \mathrm{C}$.

\section{Model performance evaluation}

Three statistical indices were selected and calculated for evaluating model performance (equation 7): i) mean absolute percentage error $(M A E)$, ii) model efficiency $(E F)$, and iii) maximum absolute percentage error $(M E)$, determined according to the following relations (Legates and McCabe Jr, 1999; Goovaerts et al., 2005):

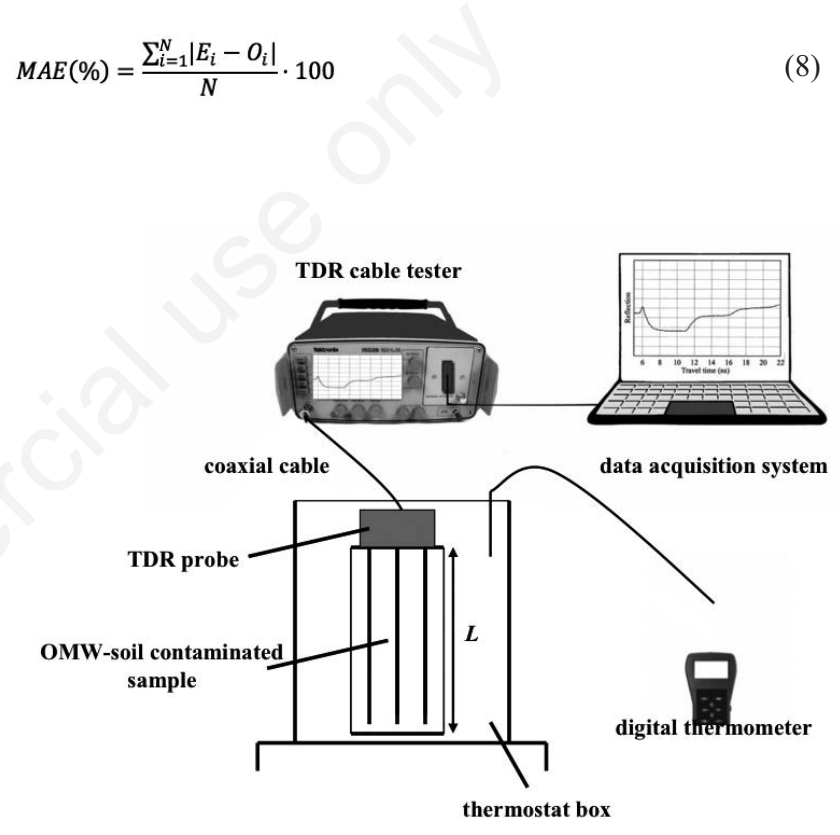

Figure 1. Experimental setup used in laboratory experiments (from Comegna et al., 2016). TDR, time domain reflectometry; OMW, olive mill wastewater.

Table 1. Main physico-chemical properties of the two soils investigated.

\begin{tabular}{|c|c|c|c|c|c|c|c|c|c|}
\hline Soil & Depth & Soil 1 & re and $\mathrm{Cl}$ e & ication ( & SDA) & Porosity & C & $E C_{\mathrm{W}}$ & $p H$ \\
\hline & $(\mathrm{cm})$ & Sand (\%) & Clay (\%) & Silt $(\%$ & & (\%) & $(\%)$ & $\left(\mathrm{dSm}^{-1}\right)$ & \\
\hline Eutric Cambisol & $0-20$ & 41.4 & 16.4 & 42.2 & Loam & 0.52 & 0.30 & 0.13 & 8.40 \\
\hline Anthrosol & $0-20$ & 15.7 & 11.6 & 72.7 & Silt Loam & 0.57 & 1.84 & 0.17 & 8.37 \\
\hline
\end{tabular}

Table 2. Main physico-chemical properties of the olive mill wastewater used in the experimentation.

\begin{tabular}{lc} 
Parameter & Value \\
$\mathrm{pH}$ & 3.85 \\
Electrical conductivity at $20^{\circ} \mathrm{C}(\mathrm{dS} / \mathrm{m})$ & 10.20 \\
\hline Dissolved oxygen: $D O(\mathrm{mg} / \mathrm{L})$ & 0.23 \\
Total organic carbon: $\mathrm{TOC}(\mathrm{mg} / \mathrm{L})$ & 6016 \\
\hline
\end{tabular}


$E F=1-\frac{\sum_{i=1}^{N}\left(E_{i}-O_{i}\right)^{2}}{\sum_{i=1}^{N}\left(O_{i}-\bar{O}\right)^{2}}$

$M E(\%)=M A X\left|E_{i}-O_{i}\right| \cdot 100$

where $E_{i}$ was the prediction (model-simulated data) and $\bar{O}$ was the true value (observed data), was the mean of the observed data, and $N$ was the number of observations.
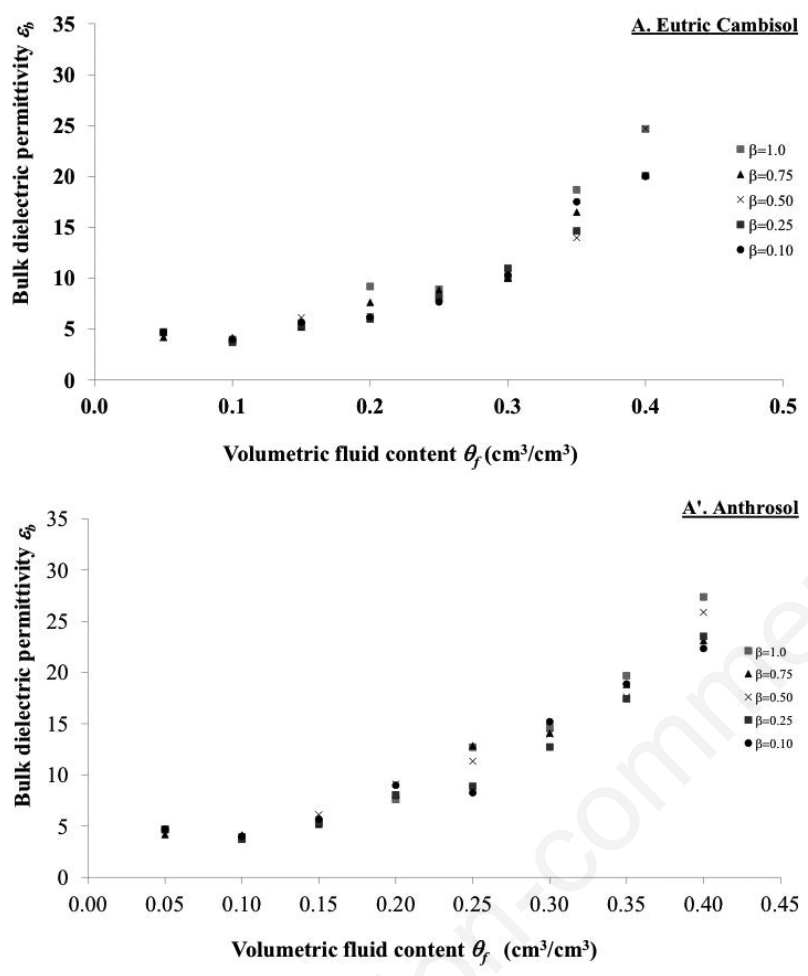

\section{Results and discussion}

\section{Dielectric characterization of olive mill wastewater-con- taminated soil}

Figures 2A-A' and B-B' show respectively the experimental $\varepsilon_{b}$ vs $\theta_{f}$ and $E C_{b}$ vs $\theta_{f}$ relationships, obtained for selected $\beta$ values. As can be observed in Figure 2A-A', in the investigated $\theta_{f}$ domain (i.e. $0.05 \leq q_{f} \leq 0.40$ ), the measured dielectric permittivity of OMW-contaminated soil samples increased overall, as the volumetric fluid content increased. At the same time, for fixed $\theta_{f}$ values, it may be
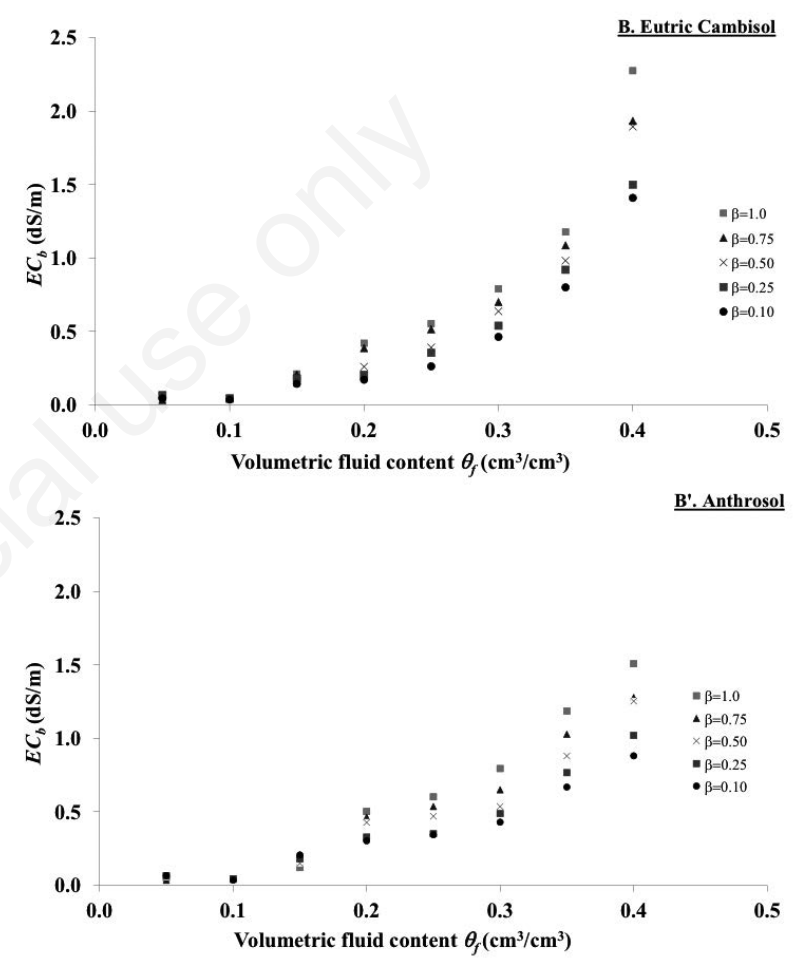

Figure 2. Effect, on the two selected soils, of volumetric fluid content $\left(\theta_{f}\right)$ on: A-A') bulk dielectric permittivity $\left(\varepsilon_{b}\right)$, and B-B') bulk electrical conductivity $\left(E C_{b}\right)$, of soil-water-OMW-air mixtures, for different $\beta$ values.

Table 3. Combinations of moisture volume $\left(V_{\mathrm{w}}\right)$ and olive mill wastewater volume (VOMW) for $\boldsymbol{\beta}$ and $\theta_{f}$ values.

\begin{tabular}{|c|c|c|c|c|c|c|c|c|c|c|c|c|c|}
\hline \multirow[b]{2}{*}{$\theta_{f}$} & \multirow[t]{2}{*}{$\begin{array}{c}\text { Volume of } \\
\text { fluids } \\
\left(\mathrm{cm}^{3}\right)\end{array}$} & \multicolumn{5}{|c|}{$\begin{array}{c}\text { Relative volume of OMW in water: } \\
\beta\end{array}$} & & \multirow[t]{2}{*}{$\begin{array}{l}\text { Volume of } \\
\text { fluids } \\
\left(\mathrm{cm}^{3}\right)\end{array}$} & \multicolumn{5}{|c|}{$\begin{array}{c}\text { Relative volume of OMW in water: } \\
\beta\end{array}$} \\
\hline & & 1 & 0.75 & 0.50 & 0.25 & 0.10 & $\theta_{f}$ & & 1 & 0.75 & 0.50 & 0.25 & 0.10 \\
\hline \multirow[t]{2}{*}{0.05} & $V_{W}$ & 0 & 13 & 27 & 40 & 48 & 0.25 & $V_{W}$ & 0 & 66 & 133 & 199 & 239 \\
\hline & $\mathrm{V}_{\text {OMW }}$ & 53 & 40 & 27 & 13 & 5 & & VOMW $_{\text {OM }}$ & 266 & 199 & 133 & 66 & 27 \\
\hline \multirow[t]{2}{*}{0.10} & $V_{W}$ & 0 & 27 & 53 & 80 & 96 & 0.30 & $V_{W}$ & 0 & 80 & 159 & 239 & 287 \\
\hline & VOMW & 106 & 80 & 53 & 27 & 11 & & VOMW & 319 & 239 & 159 & 80 & 32 \\
\hline \multirow[t]{2}{*}{0.15} & $V_{W}$ & 0 & 40 & 80 & 120 & 144 & 0.35 & $V_{W}$ & 0 & 93 & 186 & 279 & 335 \\
\hline & $\mathrm{V}_{\mathrm{OMW}}$ & 159 & 120 & 80 & 40 & 16 & & $V_{\text {OMW }}$ & 372 & 279 & 186 & 93 & 37 \\
\hline \multirow[t]{2}{*}{0.20} & $V_{W}$ & 0 & 53 & 106 & 159 & 191 & 0.40 & $V_{W}$ & 0 & 106 & 213 & 319 & 383 \\
\hline & VOMW & 213 & 159 & 106 & 53 & 21 & & VOMW & 425 & 319 & 213 & 106 & 43 \\
\hline
\end{tabular}

OMW, olive mill wastewater. 
noted that the calculated $\varepsilon_{b}$ values overlapped more or less. This means that differences in $\beta$ (i.e., differences in soil contamination levels) do not affect the dielectric response of the contaminated medium in terms of permittivity. In other words, $\varepsilon_{b}$ was not OMWsensitive. By contrast, as shown in the graphs in Figure 2B-B', especially in the $\theta_{f}$ range $0.20-0.40$, a clear correlation appears between $E C_{b}$ and $\theta_{f}$ and, for a fixed $\theta_{f}$, between $E C_{b}$ and $\beta$. Indeed, $E C_{b}$ values increased with $q_{f}$ and with $\beta$.

\section{Model calibration and validation}

In order to confirm the approach adopted, as described in section 3 above, Figures $3 \mathrm{~A}$ and $\mathrm{B}$ show the experimental (colored dots) and inferred (continuous line) $\beta v s \ln \left(E C_{b}\right)$ relationships for

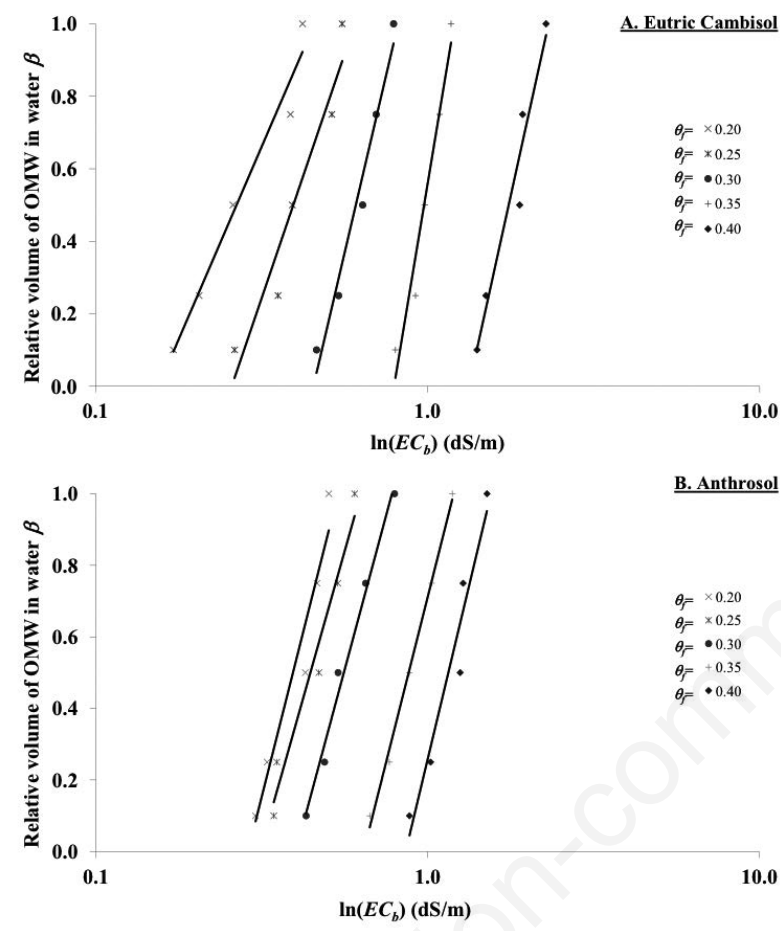

Figure 3. Experimental relationship between bulk electrical conductivity $E C_{b}$ and the relative volume of olive mill wastewater in water, for constant $\theta_{f}$ values: A) Eutric Cambisol and B) Anthrosol.

Table 4. Estimated $a_{c}, b_{1}, b_{2}$ and $b_{3}$ coefficients of $\beta v s \ln \left(E C_{b}\right)$ relationships at different $\theta_{f}$ values.

\begin{tabular}{lcccc} 
Soil & $a_{c}$ & $b_{1}$ & $b_{2}$ & $b_{3}$ \\
Eutric Cambisol & 1.185 & -16.103 & -1.367 & 2.989 \\
Anthrosol & 1.569 & -22.646 & 4.7463 & 1.927 \\
\hline
\end{tabular}

different values of the volumetric fluid content $\left(\theta_{f}\right)$. For such data, an ANCOVA analysis performed at a significance level of 0.05 confirmed a parallelism among the $\beta-\ln \left(E C_{b}\right)$ regression lines. As a consequence, a common slope $a_{c}$ can be assumed for each of the tested soils. Furthermore, as demonstrated by Figure 4A and B, the intercepts $b$ of the different $\beta-\ln \left(E C_{b}\right)$ relationships can be suitably inferred from a second order polynomial equation $\left(R^{2}\right.$ is 1.0 for the Eutric Cambisol and 0.99 for the Anthrosol). Coefficients $a_{c}, b_{1}, b_{2}$ and $b_{3}$ resulting from model calibration are shown in Table 4.

As mentioned above, the model reliability was evaluated by applying the model with the calibrated coefficients to an independent validation dataset. Figure 5 compares the computed (equation 7) and the measured volumetric OMW content. The corresponding statistical indices are reported in Table 5.

Overall, both Figure 5 and Table 5 confirmed the satisfactory agreement of the model predictions with the experimental data: the model efficiency is very close to 1 for both soils. The maximum absolute percentage error and mean absolute error were $8.8 \%$ and $3.4 \%$ for the Eutric Cambisol and 6.5\% and 2.8\% for the Anthrosol respectively.

Considering the complexity of the modelled process, these results are appreciable and validate the scientific consistency of the approach and its general applicability to determine volumetric OMW content in a contaminated medium by means of TDR.
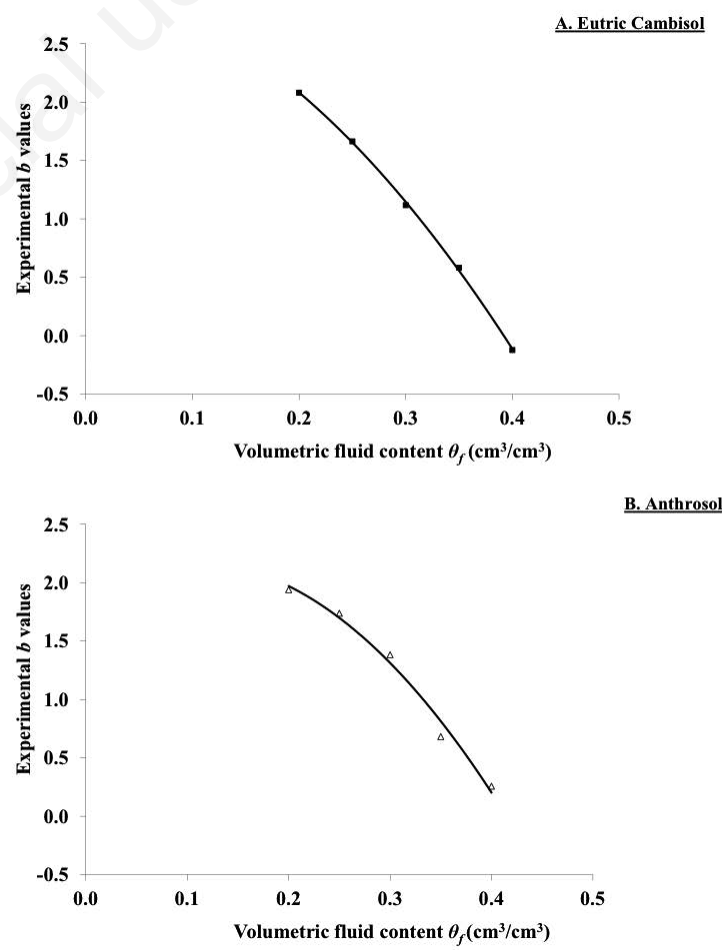

Figure 4. Experimental $b$ values of the $\beta-\ln \left(E C_{b}\right)$ relationships versus volumetric fluid content $\left(\theta_{f}\right)$ : A) Eutric Cambisol and B) Anthrosol.

Table 5. Range of model applicability and: i) mean absolute error $(M A E)$, ii) maximum absolute percentage error $(M E)$, iii) model effi-

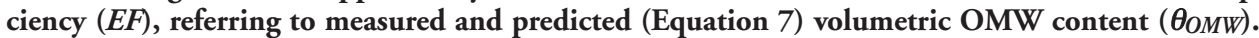

$\begin{array}{lcccc}\text { Soil } & \text { Range of model applicability } & \text { MAE (\%) } & \text { MIE }(\%) & \text { EF } \\ \text { Eutric Cambisol } & 0.20 \leq \theta_{f} \leq 0.40 & 3.4 & 8.80 & 0.95 \\ \text { Anthrosol } & 0.20<\theta_{f}<0.40 & 2.8 & 6.53 & 0.96\end{array}$




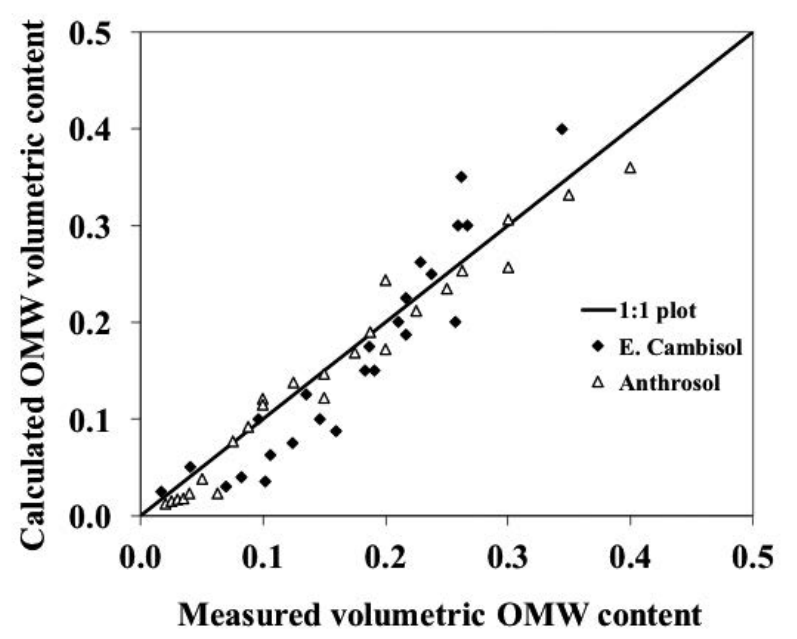

Figure 5. Calculated (Equation 7) versus measured volumetric olive mill wastewater $(\mathrm{OMW})$ content $\left(\theta_{O M W}\right)$ for the two contaminated soils.

\section{Conclusions}

In this study, we conducted a series of laboratory experiments on soil samples exposed to variable degrees of OMW contamination. The measurements of soil bulk dielectric permittivity $\left(\varepsilon_{b}\right)$ and soil bulk electrical conductivity $\left(E C_{b}\right)$ were performed simultaneously via TDR within each investigated sample. The experimental framework was set up in order to accomplish, as far as possible, a full factorial plan of electromagnetic characterization of the OMW-contaminated soil samples in the $0.05 \leq q_{f} \leq 0.40$ domain. It was shown that the presence of olive mill wastewater in the soil had a low or null effect on $\varepsilon_{b}$. However, an interesting correlation between $\theta_{O M W}$ and $E C_{b}$ was found. On the basis of the results attained, a dielectric model (Equation 7), which made it possible to quantify the volumetric OMW content, was developed and appropriately validated. This research work can be considered an enhancement in monitoring soil affected by OMW contamination using the time domain reflectometry technique.

The current database should be extended, selecting for example different pedological contexts in other Mediterranean countries with similar environmental problems. Full field-scale tests should also be carried out to evaluate the performance of the proposed model in real field conditions.

\section{References}

APHA (American Public Health Association). 1995. Standard Methods for the Examination of Water and Wastewater, 19th Edition, Washington, DC, USA.

Capasso R., Cristinzio G., Evidente A., Scognamiglio F. 1992. Isolation, spectroscopy and selective phytotoxic effects of polyphenols from vegetable waste waters. Phytochemistry 31:4125-8.

Caputo M.C., De Girolamo A.M., Volpe A. 2013. Soil amendment with olive mill wastes: impact on groundwater. J. Environ. Manage. 131: 216-21.
Colarieti M.L., Toscano G., Greco G. 2006. Toxicity attenuation of olive mill wastewater in soil slurries. Environ. Chem. Lett. 4:115-8.

Comegna A., Coppola A., Dragonetti G., Severino G., Sommella A. 2017. Interpreting TDR signal propagation through soils with distinct layers of nonaqueous-phase liquid and water content. Vadose Zone J. 16:0141.

Comegna A., Coppola A., Dragonetti G., Severino G., Sommella A., Basile A. 2013b. Dielectric properties of a tilled sandy volcanic-vesuvian soil with moderate andic features. Soil Till. Res. 133:93-100.

Comegna A., Coppola A., Dragonetti G., Sommella A. 2013a. Dielectric response of a variable saturated soil contaminated by Non-Aqueous Phase Liquids (NAPLs). Procedia Environ. Sci. 19:701-10.

Comegna A., Coppola A., Dragonetti G., Sommella A. 2016. Estimating non-aqueous phase liquid (NAPL) content in variable saturated soils using time domain reflectometry (TDR). Vadose Zone J. 15:0145.

Comegna A., Coppola A., Dragonetti G., Sommella A. 2019. A soil non-aqueous phase liquid (NAPL) flushing laboratory experiment based on measuring the dielectric properties of soilorganic mixtures via time domain reflectometry (TDR). Hydrol. Earth Syst. Sci. 23:3593-602.

Dalton F.N., Herkelrath W.N, Rawlins D.S., Rhoades J.D. 1984. Time-domain reflectometry: Simultaneous measurements of soil water content and electrical conductivity with a single probe. Science 224:989-90.

Francisca M., Montoro M.A. 2012. Measuring the dielectric properties of soil-organic mixtures using coaxial impedance dielectric reflectometry. J. Appl. Geophys. 80:101-9.

Giese K., Tiemann R. 1974. Determination of the complex permittivity from thin-sample time domain reflectometry: Improved analysis of the step response waveform. Adv. Mol. Relaxat. Process. 7:45-9.

Goovaerts P., AvRuskin G., Meliker J., Slotnick M., Jacquez G., Nriagu J. 2005. Geostatistical modeling of the spatial variability of arsenic in groundwater of southeast Michigan. Water Resour. Res. 41:W07013.

Haridy S.A., Persson M., Berndtsson R. 2004. Estimation of LNAPL saturation in fine sand using time-domain reflectometry. Hydrol. Sci. 49:987-1000.

Huisman J.A., Hubbard S.S., Redman J.D., Annan A.P. 2003. Measuring soil water content with ground penetrating radar: A review. Vadose Zone J. 2:476-91.

IRSA-CNR. 2003. Metodi analitici per le acque. Volume Primo, pp 781-789.

Isidori M., Lavorgna M., Nardelli A., Parrella A. 2005. Model study on the effect of 15 phenolic olive mill wastewater constituents on seed germination and vibro fischeri metabolism. J. Agric. Food Chem. 53:8414-7.

IUSS Working Group WRB. 2006. World reference base for soil resources 2006: A framework for international classification, correlation and communication. 2nd ed. World Soil Resour. Rep. 103, FAO, Rome, Italy.

Jung S., Drnevich V.P., Abou Najm M.R. 2013. New methodology for density and water content by time domain reflectometry. J. Geotech. Geoenviron. Eng. 139:659-70.

Kavvadias V., Doula M., Theocharopoulosm S. 2014. Long-term effects on soil of the disposal of olive mill waste waters (OMW). Environ. Forens.15:37-51.

Legates D.R., McCabe Jr G.J. 1999. Evaluating the use of "goodness-of-fit" measures in hydrologic and hydroclimatic model 
validation. Water Resour. Res. 35:233-41.

Mekki A., Dhouib A., Sayadi S. 2006. Changes in microbial and soil properties following amendment with treated and untreated olive mill wastewater. Microbiol. Res. 161:93-101.

Moroizumi T., Sasaki Y. 2006. Estimating the nonaqueous-phase liquid content in saturated sandy soil using amplitude domain reflectometry. Soil Sci. Soc. Am. J. 72:1520-6.

Or D., Jones S.B., VanShaar J.R., Humphries S., Koberstein L. 2004. Win TDR Soil Analysis Software User Guide. Utah State University, USA.

Persson M., Berndtsson R. 2002. Measuring nonaqueous phase liquid saturation in soil using time domain reflectometry. Water Resour. Res. 38:1-8.

Piotrowska A., Rao M.A, Scotti R., Gianfreda L. 2011. Changes in soil chemical and biochemical properties following amendment with crude and dephenolized olive mill waste water (OMW). Geoderma 161:8-17.
Redman J.D., De Ryck S.M. 1994. Monitoring non-aqueous phase liquids in the subsurface with multilevel time domain reflectometry probes. Proc Symp. on Time Domain Reflectometry in Environmental, Infrastructure, and Mining Applications, Evanston, IL. Spec. Publ. SP19-94. U.S. Bur. of Mines, Washington, DC, USA.

Rinaldi V.A., Francisca F.M. 2006. Removal of Immiscible Contaminants from Sandy Soils monitored by Means of Dielectric Measurements. J. Environ. Eng. 132:931-9.

Robinson D.A., Jones S.B., Wraith J.M., Or D. 2003. A review of advances in dielectric and electric conductivity measurements using time domain reflectometry. Vadose Zone J. 2:444-75.

Sahraoui H., Kanzari S., Hachicha M., Mellouli H.J. 2015. Olive mill wastewater spreading effects on hydraulic soil properties. Experiment 30:2002-2011, 2015.

Topp G.C., Davis J.L., Annan A.P. 1980. Electromagnetic determination of soil water content: Measurement in coaxial transmission lines. Water Resour. Res. 16:574-82. 